\title{
Focal nodular hyperplasia of the liver: a rational approach to treatment
}

\author{
A. P. MOWAT, P. GUTJAhr, B. PORTMANN, J. L. DAWSON, AND \\ ROGER WILLIAMS
}

From the Department of Surgery, Child Health, and the Liver Unit, King's College Hospital and Medical School, London, and the Universitäts-Kinderklinik Mainz, Germany

SUMMARY Focal nodular hyperplasia of the liver in a 3 year old child has been successfully treated by ligation of the hepatic artery branches supplying the lesion. The prominence of the abnormal vasculature in the lesion and its possible aetiological involvement is stressed. Because of the risks of partial hepatectomy, hepatic artery ligation is suggested as the treatment of choice for focal nodular hyperplasia.

There is considerable debate on the aetiology and treatment of focal nodular hyperplasia, a slowgrowing, well demarcated, benign tumour of liver parenchyma. Pathologically, it is characterized by a central scar with radiating fibrous septa containing proliferating bile ducts and blood vessels which show medial and intimal hypertrophy. Isolated arteries may be seen within the hepatic parenchyma, which is itself essentially normal having only minor alterations of growth patterns and vascular relationships. The current evidence suggests that the lesion is not an adenoma but a hamartomatous malformation with considerable arterial anomalies (Phillips et al., 1973; Whelan et al., 1973). In the adult, such lesions are commonly asymptomatic but in children may cause abdominal distension and pain by torsion or haemorrhage into the peritoneum. In such circumstances, resection has been advised but published results are poor (Whelan et al., 1973). We report the successful treatment of such a lesion, in which hepatic arterial ligation was followed by complete clinical regression.

\section{Case report}

In July 1973, during a clinical examination for an upper respiratory tract infection, a male child was found to have a palpable mass in the right upper quadrant of the abdomen which had not been evident to the same examiner six weeks previously. The child had been born on 14 October 1970 after a 37-week uncomplicated pregnancy. He was the second child of healthy, unrelated parents and weighed $2.8 \mathrm{~kg}$ at birth. Neither he nor his family had any history of significant illnesses. The only abnormal physical finding was a hard mass, continuous with the liver and measuring between 5 and 7 $\mathrm{cm}$ where it abutted the abdominal wall. A systolic bruit was heard all over the mass.

\section{INVESTIGATIONS}

Peripheral blood count, bone marrow, and standard liver function tests were all normal. Serum alphafetoprotein and hepatitis B surface antigen were negative. The HLA type was $2,5,9,12$. Radiographs of chest, skull, and skeleton were normal.

The liver scan had a reduced peak count rate of $30 \mathrm{~K}$ and showed an enlargement of the liver. No definite filling defects were seen, but the uptake of colloid around the hilum and lower border of the right lobe was patchy. Coeliac artery angiography showed tumour circulation mainly in the right lobe but extending to the midline. A large tumour with a highly vascular surface was seen at laparoscopy protruding from the right lobe of the liver, and extending dorsally beneath the ligamentum hepatoduodenale without infiltrating it. The presumed diagnosis at this stage was hepatoblastoma. Percutaneous liver biopsy produced fragments of pale grey tissue which appeared, on histological examination, to be fibrous tissue suggestive of focal nodular hyperplasia. However, the biopsy material was too small and distorted to allow a confident diagnosis.

\section{LAPAROTOMY FINDINGS AND SUBSEQUENT COURSE}

A wedge biopsy of the tumour mass indicated a diagnosis of focal nodular hyperplasia. The mass was 
not resectable because of its very vascular nature (Fig. 1) and it was decided to ligate the three branches of the hepatic artery which entered the tumour at the portahepatis. As the cystic artery was also tied, a cholecystectomy was carried out.

The patient's recovery was uneventful. On leaving hospital on the tenth postoperative day the liver mass had not changed clinically from its preoperative state, but in the subsequent 12 weeks it gradually became smaller. Nine months later, there was no abdominal distension, and the abnormal liver mass had regressed to a firm area approximately $2 \times 3 \mathrm{~cm}$ in dimension. Liver function tests, including serum alkaline phosphatase levels, and the liver scan were normal. During the subsequent two and a half years, the child has grown at a normal rateand all investigations remain normal.

\section{LIVER HISTOLOGY}

Biopsy material taken from the nodular lesion at the time of surgery showed the liver tissue to be divided into nodules by thin bands of fibrous tissue within which there were proliferating bile ducts, abnormal dilated thin-wall blood vessels, and prominent hyperplastic small arteries (Fig. 1). The hepatic parenchyma showed slight disturbance of the normal architecture but the hepatocytes and their nuclei were normal. Endothelial cells were prominent within the sinusoids. There were no features of malignancy.

A percutaneous Trucut biopsy of the hard nodule, taken nine months after hepatic artery ligation, contained dense fibrous tissue with proliferating small bile ducts and ductules, an increased number of blood cells, and scattered mononuclear cells. A few irregular nodules of liver parenchyma were seen in the fibrotic areas (Fig. 2).

\section{Discussion}

Focal nodular hyperplasia is a very rare condition but since Edmondson (1956) first introduced the

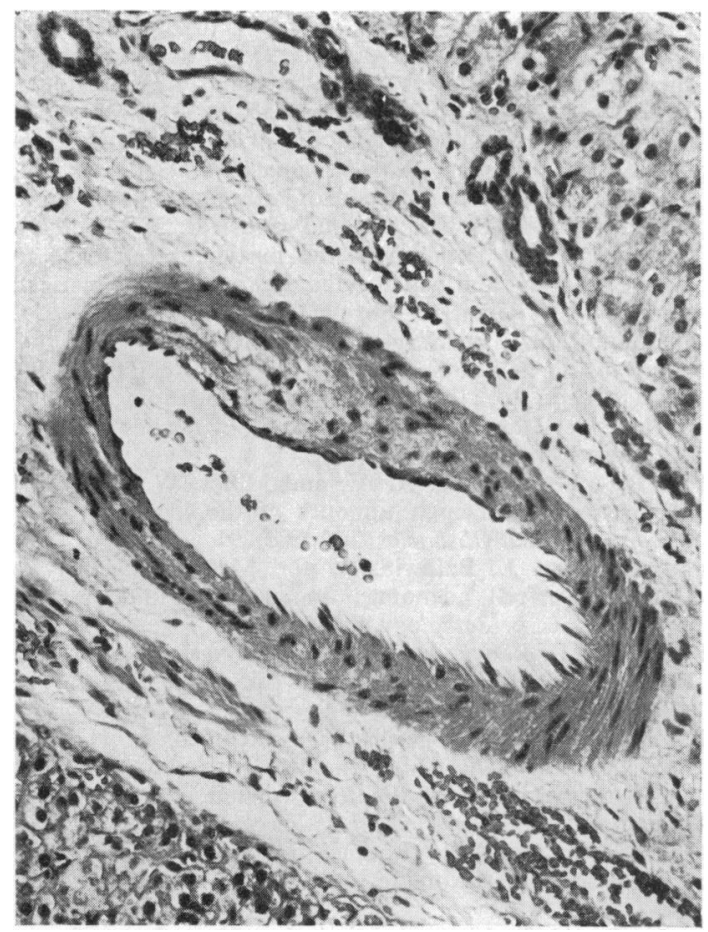

Fig 1

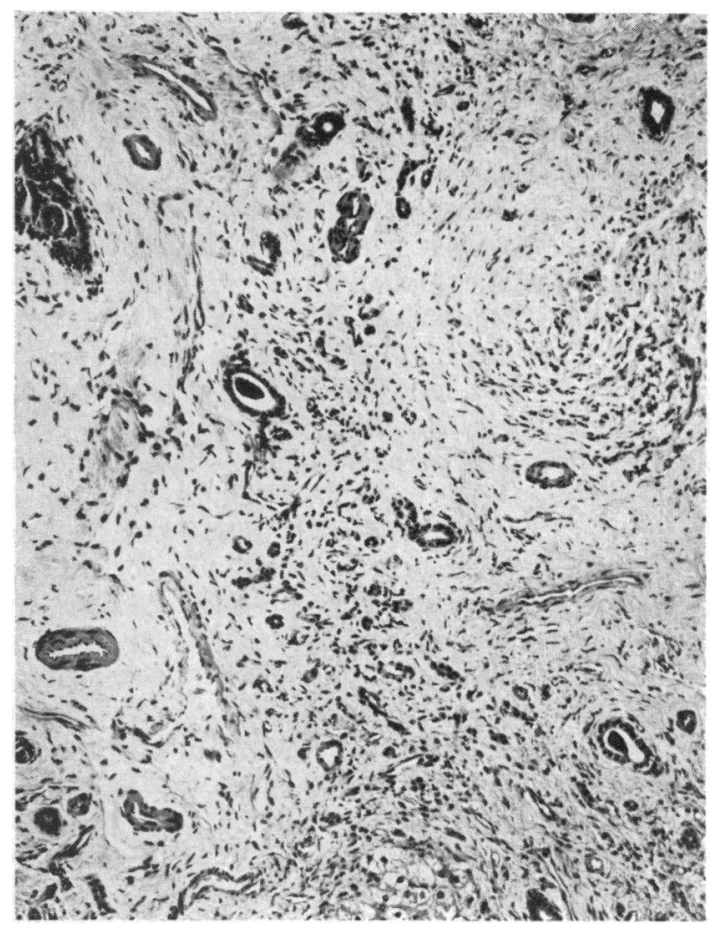

Fig 2

Fig. 1 Section from surgical biopsy showing normal hepatic parenchyma on either side of a band of fibrous tissue which contains not only a large branch of the hepatic artery showing medial hypertrophy, but very numerous small thin-wall blood vessels, emphasising the vascular component of the lesion. Haematoxylin and eosin, $\times 160$.

Fig. 2 Abnormal blood vessels and numerous bile ductules with a mononuclear cell infiltrate in dense fibrous tissue from the percutaneous liver biopsy from the hard mass persisting nine months after he patic artery ligation. $H$ and $E, \times 65$. 
term 20 years ago evidence has gradually accumulated confirming its largely benign nature, its clinical course, and the main histological findings. Controversy persists over many aspects of the disorder, including aetiology. The condition has been confused with partial nodular transformation in which similar hepatic nodules are present around the hilar region causing portal hypertension. In both conditions, much of the hepatic parenchyma is normal. Many other synonyms have been suggested for focal nodular hyperplasia, but strong evidence was provided by Phillips and his colleagues (1973) for classifying the lesion as a hamartoma because of the large abnormal veins and arteries at the periphery, the development of fibrous tissue and proliferation of bile ducts, and the persistent organisation of hepatocytes in single-cell plates. In contrast, in hepatic adenoma the hepatocytes are often in doublecell plates and, although they have a rich sinusoidal vascular network, they have no large vessels related to the lesion and no excess of fibrous tissue or bile duct reduplication.

Although it has been suggested that malignant change may occur in focal nodular hyperplasia, many reports emphasize the benign nature of the lesion (Edmondson, 1956; Whelan et al., 1973). The only electronmicroscopy abnormality in focal nodular hyperplasia is the microvilli suggesting that the lesion is not pre-malignant. Because focal nodular hyperplasia is frequently associated with vascular anomalies (Jouanneau et al., 1963; Thomas et al., 1966; Palubinskas et al., 1967; Malt et al., 1970; Whelan et al., 1973) and there is an increased incidence of the lesion in livers with cavernous haemangiomata (Benz and Baggenstoss, 1953) and in hereditary haemorrhagic talangiectasia (Zelman, 1962), it has been postulated that focal nodular hyperplasia arises secondary to the vascular lesion. The marked shrinkage of the lesion in the present case after hepatic artery ligation is further suggestive evidence in favour of a vascular aetiology. Experimental arterialisation of the liver in dogs causes secondary vascular changes within the liver, fibrosis, and bile duct proliferation, although there is no true nodular hyperplasia (Zuidema et al., 1963).

The percutaneous liver biopsy in this case did suggest the correct diagnosis, although many of the clinical features pointed to a rapidly growing malignant tumour. The lack of systemic symptoms such as anorexia, weight loss, and the apparent hardness of the lesion might also have suggested a hamartoma. However, focal nodular hyperplasia accounted for less than $1 \%$ of 400 hepatic tumours in infancy seen by over 100 North American paediatric surgeons during a 10 year period (Exelby et al., 1974). The normal serum alphafetoprotein concentration is not particularly helpful since up to $40 \%$ of infants with hepatoblastoma and $60 \%$ with hepatocellular carcinoma may not have elevated levels (Exelby et al., 1974).

To date, the treatment usually employed has been a partial hepatectomy. The mortality of such an operation, however, is appreciable $-25 \%$ of 86 children operated on for malignant hepatic tumour died (Exelby et al., 1974). Two adult patients with focal nodular hyperplasia died after a partial hepatectomy and a child operated on by the same group had a difficult postoperative course (Whelan et al., 1973). There are no previous reports of hepatic artery ligation for this lesion but the results in our patients certainly suggest that this approach merits further trial.

\section{References}

Benz, E. J., and Baggenstoss, A. H. (1953). Focal cirrhosis of the liver: its relation to the so-called hamartoma (adenoma, benign hepatoma). Cancer, 6, 743-755.

Edmondson, H. A. (1956). Tumours of the liver and intrahepatic bile ducts. In Atlas of Tumour Pathology, Sect. 7, fasc. 25, Armed Forces Institute of Pathology: Washington.

Exelby, P. R., Filler, R. M., and Grosfeld, J. L. (1975). Liver tumors in children in the particular reference to hepatoblastoma and hepatocellular carcinoma-American Academy of Pediatrics Surgical Section Survey-1974. Journal of Paediatric Surgery, 10, 329-337

Jouanneau, P., Laumonier, R., Laquerriere, R., Évreux, R., and Chapelle, M. (1963). Apropos d'un adénome du foie. Archives des Maladies de l'Appareil Digestif et des Maladies de la Nutrition, 53, 940-948.

Malt, R. A., Hershberg, R. A., and Miller, W. L. (1970). Experience with benign tumours of the liver. Surgery., Gynaecology and Obstetrics, 130, 285-291.

Palubinskas, A. J., Baldwin, J., and McCormack, K. R. (1967). Liver-cell adenoma: angiographic findings and report of a case. Radiology, 89, 444-447.

Phillips, M. J., Langer, B., Stone, R., Fisher, M. M., and Ritchie, S. (1973). Benign liver cell tumours. Cancer (Philadelphia), 32, 463-470.

Thomas, P. A., McCusker, J. J., Merringen, E. H., and Conte, N. F. (1966). Lobar cirrhosis with nodular hyperplasia (hamartoma) of the liver treated by left hepatic lobectomy. American Journal of Surgery, 112, 831-834.

Whelan, T. J., Baugh, J. H., and Chandor, S. (1973). Focal nodular hyperplasia of the liver. Annals of Surgery, 177, 150-158.

Zelman, S. (1962). Liver fibrosis in herediatry hemorrhagic talangiectasia. Archives of Pathology, 74, 66-72.

Zuidema, G. D., Gaisford, W. D., Ábell, M. R., Brody, T. M., Neill, S. A., and Child, C. G. (1963). Segmental portal arterialization of canine liver. Surgery, 53, 689-698. 